\title{
INFORMATION SHARING AND SPILLOVERS: EVIDENCE FROM FINANCIAL ANALYSTS
}

\author{
Byoung-Hyoun Hwang, José María Liberti, and Jason Sturgess*
}

This Draft: October 2017

\begin{abstract}
We study how information sharing within an organization affects individual performance. We look at situations in which the same analyst, while working at the same broker, covers multiple mergers and acquisitions (M\&As), in particular the acquirer prior to the M\&A and the merged firm thereafter. We find that earnings forecasts for the merged firm are significantly more accurate when the analyst has a colleague (working at the same broker) covering the target prior to the M\&A. This holds particularly true if acquirer- and target-analysts reside in the same locale, if they are part of a smaller team, and if the target-analyst is of higher quality. Our findings highlight the importance of information spillovers on individual performance in knowledge-based industries.
\end{abstract}

JEL Classification: G20, J23, J24, J31, J62, L23

Keywords: Information Spillovers, Knowledge-based industries, Analyst performance

\footnotetext{
* Hwang is primarily with the Cornell SC Johnson College of Business, Dyson School of Applied Economics and Management, Cornell University, Warren Hall 310E, Ithaca, NY 14853, USA; Hwang is also with the Korea University Business School, Korea University, Anam-dong, Seongbuk-gu, Seoul, Korea 136-701. Liberti is with the Kellogg School of Management, Northwestern University, 2211 Campus Dr., Evanston, IL 60208; Liberti is also with the Kellstadt Graduate School of Business, DePaul University, One East Jackson Boulevard, Chicago, IL 60604. Sturgess is with the School of Economics and Finance, Queen Mary University of London, Mile End Rd, London E1 4NS. Email: bhwang@cornell.edu, j-liberti@kellogg.northwestern.edu and j.sturgess@qmul.ac.uk. We thank Jonathan Clarke (discussant), Jennifer Juergens, Marcin Kacperczyk (discussant), Alexander Ljungqvist, David Matsa, Paola Sapienza, Amit Seru, Per Strömberg Luigi Zingales, and seminar participants at the 2014 AFA meetings, 2015 EFA Meetings, the University of Cambridge, the Cass Business School, DePaul University, Florida State University, George Mason University, Georgetown University, Michigan State University, the University of Illinois at Chicago, the University of Illinois at Urbana-Champaign, and the University of Warwick for helpful comments.
} 


\section{Introduction}

To what degree do organizational attributes affect individual performance in knowledge-based industries?

If we were to randomly move an individual from a position at a given firm to an identical position at another firm, how much would that individual's performance change? For what kinds of positions and environments should we expect the effect of organization on performance to be the greatest? These are some of the most fundamental questions pertaining to the theory of the firm and they have inspired a large body of work. ${ }^{1}$

Unfortunately, these are also extremely difficult questions to tackle empirically: Employees never move randomly across firms and any change in performance around a job change may be due to innate ability. We also cannot fairly contrast the performance of two individuals working at two different firms and attribute any observed difference in performance to differences in organizational attributes across these two firms as the assignment of individuals to firms itself cannot be thought of as occurring independently of individuals' innate abilities. Further complicating matters, individual performance is rarely observable. ${ }^{2}$ In most cases, we observe only firm-level outputs. Yet firm-level outputs are the result of a complex combination of inputs from many individuals and firm-level resources.

In this paper, we introduce a setting that, we believe, addresses these challenges. We then use this setting to test whether organization affects individual performance by creating an environment in which employees interact with and learn from each other (= treatment effect), or whether organizational design does not affect individual performance and "higher-performing firms" simply hire more productive individuals (= selection effect).

\footnotetext{
${ }^{1}$ Since the seminal work of Coase (1937) economists have argued about the origins, role, and rationales of power in the theory of the firm. One line of argument in a long-standing debate on organizations is that ownership of physical assets is not the only source of power within a firm. Hart (1989) argues that, to the extent that there are complementarities across employee tasks, the total output of a group of workers may exceed the sum of the workers' individual outputs. Klein (1988) similarly distinguishes physical from human asset specificity by pointing out that an organization is embedded in the human capital of a firm's employees but is greater than the sum of its parts. Rajan and Zingales (1998, 2001) examine how human capital might define firm boundaries.

${ }^{2}$ In asset-based industries, individual performance has been examined for simple tasks where output and performance are verifiable (for example, see the analysis of incentives and performance using fruit-pickers in Bandiera, Barankay, and Rasul (2005)). However, this issue is less straightforward in knowledge-based industries because individuals working for firms in those industries rarely produce output in their own names. Even where they do, it may not be easy to verify either the quality or performance of the output. A notable example of a study addressing such questions in a knowledge-based industry is Ewens and Rhodes-Kropf (2015), who explore whether venture capitalists' skills are portable across venture capital firms and whether these firms shape the talent of venture capitalists.
} 
Our identification comes from financial analysts' coverage of mergers and acquisitions (M\&As). Our focus on analysts allows us to quantify individual performance as we can directly observe one of the most important performance outputs that financial analysts produce, namely earnings forecasts. We also have an objective benchmark, in the form of actual reported earnings, against which earnings forecasts can be compared.

More importantly, we believe our analyst/M\&A setting represents a quasi-natural experiment that provides plausibly random variation in the treatment effect of firm-level resources. We compare, for a given M\&A, the accuracy of an analyst's earnings forecasts for the acquirer firm prior to the M\&A with the accuracy of her forecasts for the firm that comes out of the M\&A. We exploit two sources of variation: Our first source of variation comes from evaluating the performance of "Type 1 analysts" with that of "Type 2 analysts." Type 1 analysts are acquirer analysts who work for brokerages that, prior to the M\&A, only cover the acquirer (and not the target). Type 2 analysts are acquirer analysts who work for brokerages that, prior to the M\&A, also cover the target through the employment of a second analyst. If analysts rely heavily on broker-level resources such as colleagues, Type 2 analysts, who have in-house colleagues covering targets prior to M\&As, should be at a significant advantage. In contrast, if organization does not affect individual performance and performance resides solely with analysts and the person-specific capital they have acquired over their careers, we should observe no performance differential between these two analyst types.

Our second source of variation comes from comparing the performance of Type 2 analysts with that of "Type 3 analysts," defined here as analysts that, themselves, cover both the acquirer and the target prior to the M\&A. As noted above, Type 2 analysts cover the acquirer firm and have in-house colleagues covering the target prior to the M\&A. If performance resides entirely with brokers, we should observe no meaningful performance difference between Type 3 and Type 2 analysts. On the other hand, if some brokerspecific knowledge is "lost in translation," then analysts that, themselves, cover both the acquirer and the target should be at an advantage relative to acquirer-analysts who "only" have in-house colleagues covering the target. 
To isolate the treatment effect from potential selection effects that typically plague this literature, we examine individual performances across M\&As for which the same individuals working at the same brokerage organizations represent distinct analyst types. To illustrate by example, consider GoldmanSachs-Analyst A covering two M\&As. For the first M\&A, the analyst covers the acquirer only; she has no in-house colleague covering the target prior to the M\&A (= Type 1). In the second M\&A, the analyst covers the acquirer; she also has an in-house colleague covering the target (= Type 2). We compare GoldmanSachs-Analyst A's performance when she is of Type 1 to her performance when she is of Type 2 .

Selection explains the matching of Analyst A with Goldman Sachs. Since we examine differences in performance between two M\&As for the same analyst working at the same brokerage, we essentially hold selection constant. Further, we include M\&A fixed effects to mitigate the concern that analyst type and performance correlate with M\&A characteristics. Put together, we believe our research design provides a relatively clean estimate for the effect of organization on individual performance.

To preview our main results, we find that forecast errors for newly merged firms are higher than those for acquirers prior to M\&As, consistent with newly merged firms' earnings being more uncertain and more difficult to forecast than those of acquirer firms considered by themselves (at least in the initial period after the M\&A). More importantly in the context of this study, acquirer-analysts do a substantially better job at predicting earnings for newly formed firms when they have colleagues covering targets prior to M\&As. This result suggests that organization affects individual performance.

We also find that analysts that, themselves, cover both the acquirer and the target outperform acquirer-analysts who "only" have colleagues covering the target, suggesting that, while organization affects individual performance, information can be lost in translation due to the presence of communication and coordination costs.

The ability to transfer information is likely affected by a range of factors. Radner (1993), Bolton and Dewatripont (1994), Aghion and Tirole (1997), Garicano (2000), Stein (2002), and Garicano and Hansberg (2006) explore how organizational design and allocation of tasks affect incentives to collect and use information. A central idea in this literature is that information, particularly when it is soft and 
subjective in nature, becomes increasingly harder to share as geographical and hierarchical distance increases. ${ }^{3}$ Coordinating a group of complementary specialized workers also becomes more costly as the number of specialists in a team increases (Becker and Murphy (1992)).

Our results corroborate these views. While performance generally improves when an acquireranalyst has an in-house colleague covering a target, such "information spillover effect" is strongest when acquirer and target-analysts reside in the same locale and when acquirer- and target-analysts work within a small team.

In addition to location and team size, our spillover effect is likely a function of the quality of colleagues. In line with this view, we find that the information spillover effect is particularly strong when an acquirer-analyst's colleague is an Institutional Investor All-Star Analyst. Relatedly, we find that the spillover effect is stronger when a target-analyst has been covering the corresponding target firm for a longer time period and, as such, likely has a better understanding of that firm.

We also study the impact of industry specialization on performance. Analysts or brokerages may strategically specialize in certain industry sectors. To the extent that industry specialization is correlated with analyst type, specialization may partially account for our findings. We find that, on average, analysts perform better if M\&As are in their industries of primary expertise. However, we also find that specialization does not explain or dampen the information spillover effect that we document.

Our study addresses at least three lines of research. First, our paper contributes to the literature on the theory of the firm and the role of human capital. ${ }^{4}$ Prior work, such as Mas and Moretti (2009), who study peer effects among cashiers at a supermarket, provides valuable evidence on productivity spillovers among "lower-skilled workers." To the best of our knowledge, our study is the very first to quantify the degree to which high-skilled employees in knowledge-based industries owe their success to interactions with their colleagues.

\footnotetext{
${ }^{3}$ Petersen and Rajan (2002), Mian (2006), Landier, Nair, and Wulf (2009), Liberti and Mian (2009), Agarwal and Hauswald (2010), Seru (2012), Liberti, Seru and Vig (2017), and Liberti (2017) study the effects of geographical and hierarchical distance on communication, production of information, and firm-level decision-making.

${ }^{4}$ For example, Kim, Morse, and Zingales (2009) examine research productivity at elite universities and question whether these universities have lost their competitive edge.
} 
By studying information sharing among financial analysts, our work also complements recent work that examines information flows among (other) financial market participants, such as mutual fund families (Sialm and Tham 2016), institutional investors that trade debt and equity (Ivashina and Sun 2011), banks and mutual funds in the same financial conglomerate (Massa and Rehman 2008), and corporate boards (Cohen, Frazzini, and Malloy 2008).

Finally, our work adds to the literature on professional forecasters. Evidence reported in the accounting and finance literature implies that financial analysts significantly alter market expectations (e.g., Stickel 1995, Womack 1996, Kothari 2001), in particular during times of economic uncertainty (Loh and Stulz 2017) and when the firms covered have many intangible assets (Gupta-Mukherjee 2014). Successful analysts quickly earn "superstar" status via high-profile awards, press coverage, and lucrative compensation packages. Such accolades are predicated on the assumption that a large portion of an analyst's performance is person-specific and portable, i.e., independent of the brokerage employing the analyst in question. In this study, we provide evidence that individuals owe much of their success to the organizations that employ them. A superstar moving across organizations may thus be unable to maintain her customary level of performance at her new employer. ${ }^{5}$

\section{Data}

We focus on M\&As that involve publicly traded acquirers and publicly traded targets. We identify target firms in the CRSP database via the delisting file and by reference to whether a security is marked by a firstdigit delisting code of 2 or 3 . The delisting file provides us with the PERMNO of the disappearing target firm as well as the PERMNO of the acquirer firm, which overwrites the PERMNO of the disappearing firm. Our sample period runs from 1984 through 2011.

\footnotetext{
${ }^{5}$ Groysberg, Lee, and Nanda (2008) and Groysberg (2010) study whether star analysts' knowledge is portable across brokerages. After examining the career moves of star analysts, they conclude that those who switch firms suffer a decline in performance.
} 
We merge the PERMNOs of acquirers and targets with data from the Institutional Brokers Estimates System (IBES) database, which contains analyst earnings forecasts and actual reported earnings data. We measure performance using the scaled forecast error $(F E)$. In particular, for each analyst $i$ working for broker $j$ and following the acquirer prior to M\&A $m$ and the new firm that comes out of the M\&A, we compute $F E$ for quarterly earnings $t$ in the two-year window around the effective date of the M\&A. ${ }^{6} F E$ is defined as the absolute difference between analyst $i$ 's most recent earnings-per-share (EPS) forecast and the actual announced EPS divided by the stock price as of the corresponding fiscal quarter end. We require EPS forecasts to be issued/updated at least once in the three months prior to the earnings announcement:

$$
F E_{i, j, m, t}=\left|\frac{\text { forecast }_{i, j}\left(E P S_{m, t}\right)-E P S_{m, t}}{P_{m, t}}\right|
$$

On average, the scaled forecast error in our sample is $0.172 \%$.

To isolate the treatment effect of organization on analyst performance from selection effects, we exploit variation in the coverage of targets within analyst-broker, i.e., for the same analyst working at the same brokerage. As mentioned in the introduction, we classify each analyst as a Type 1, Type 2, or Type 3 analyst. To reiterate the differences between analyst types and to illustrate our empirical design, we offer the following example:
M\&A 1: Analyst $1_{\text {Broker A covers Acquirer }}$
(Analyst $1 \equiv$ Type 1 )
M\&A 2: Analyst $1_{\text {Broker } A}$ covers Acquirer, Analyst $2_{\text {Broker A }}$ covers Target $\quad$ (Analyst $1 \equiv$ Type 2)
M\&A 3: Analyst $1_{\text {Broker } A}$ covers Acquirer and Target $\quad$ (Analyst $1 \equiv$ Type 3)

We study the performance of the same analyst working at the same broker (here, Analyst 1, who works for Broker A) across the above three M\&As. If organization affects performance, Analyst 1 should do a better job covering the newly formed firm when she is of Type 2 than when she is of Type 1 . If broker-

\footnotetext{
${ }^{6}$ In Section 5, we show that our results are robust to alternate event windows. We focus on analysts that follow the acquirer prior to the M\&A (as opposed to those that follow the target prior to the M\&A) because the acquirer is generally much larger than the target and around $91 \%$ of acquirer-analysts continue to cover the newly formed firm.
} 
specific knowledge is lost in translation, Analyst 1 should perform better when she is of Type 3 than when she is of Type 2 .

In our analysis, we consider only analyst-broker pairs that exhibit variation in type across multiple M\&As. Our final sample contains 2,394 analysts working at 215 brokerages covering 2,403 acquirers, resulting in 15,939 analyst-broker-stock pairs.

Table 1 provides descriptive statistics. On average, acquirer firms are approximately six times larger than target firms, with around seventy percent of M\&As involving firms within the same Global Industry Classification Standard (GICS) sectors (hereafter referred to as "related M\&As"). The number of analysts following an acquirer prior to an M\&A is approximately three times that of the number following a target.

Table 2 presents descriptive statistics for the financial analysts included in our final sample. 10,921 out of the 15,939 analyst-broker-firm pairs (or 69\%) represent cases in which analysts are of Type 1, 1,468 (or 9\%) represent cases in which analysts are of Type 2, and 3,550 (or 22\%) represent cases in which analysts are of Type 3. Note that any analyst-broker pair appears multiple times across the various analysttype columns in Table 2, depending on how many M\&As the analyst-broker pair covers and to which type the analyst belongs for a given M\&A.

Table 2 shows that Type 1 analysts tend to cover smaller acquisitions (as approximated by the size of a target). When analysts are of Type 2, they tend to follow larger acquirers. When analysts are of Type 3, they tend to cover larger acquisitions. Importantly, the scaled forecast error in the period prior to an M\&A is neither economically nor statistically different across analyst types.

Considering other analyst characteristics, we find that neither forecast horizon nor change in forecast bias differ across analyst type. ${ }^{7}$ We also find no meaningful difference in the number of years the

\footnotetext{
${ }^{7}$ Hong and Kacperczyk (2010) show that forecast bias increases when brokerage-level M\&As lead to a decrease in the number of analysts. In our setting, the number of analysts covering a newly formed firm increases compared with the number of analysts covering an acquirer prior to an M\&A. Correspondingly, we observe a small decrease in bias around M\&As. Thus, the increase in forecast error we observe is unlikely to be the result of an increase in bias due to a decrease in competition, as in Hong and Kacperczyk.
} 
analyst has been covering the acquirer, number of stocks covered, number of sectors covered and fraction of analysts based in New York City.

In untabulated analyses, we also compare our sample with the universe of IBES analysts. Our sample captures approximately half of the analysts in the IBES universe. On average, the analysts in our sample are similar to those in the IBES universe in terms of number of industries covered, location, and average forecast errors, although they tend to cover a greater number of firms and are slightly more experienced (results available upon request).

\section{Empirical Design}

In our empirical analysis, we measure the effects of information spillovers on performance by estimating a regression equation of the change in forecast error, $\Delta F E_{i, j, m, t}=\overline{F E_{l, j, m, p o s t}}-\overline{F E_{l, j, m, p r e}}$, on analyst type. The regression is estimated at the analyst-broker-M\&A level.

The regression equation is as follows:

$$
\Delta F E_{i, j, m, t}=\alpha_{i, j}+\alpha_{m}+\beta_{1} \text { Type } 2_{i, j, m, t}+\beta_{2} \text { Type } 3_{i, j, m, t}+X \delta+\varepsilon_{m, i, j, t},
$$

where $\Delta F E_{i, j, m, t}$ is the change in the absolute forecast error of analyst $i$, employed by brokerage $j$ and covering the acquirer in M\&A $m$ at time $t ; \alpha_{i, j}$ and $\alpha_{m}$ are analyst-broker and M\&A fixed effects, respectively. Type 2 and Type 3 equal one if analysts are of Type 2 and Type 3, respectively. Type 1 observations represent our counterfactual. $X$ includes various controls to be detailed below. Standard errors account for correlations across observations of a given analyst-broker and M\&A.

Including analyst-broker fixed effects ensures that we are making comparisons within an individual-organization match, which, as we discuss above, absorbs selection effects. Including M\&A fixed effects addresses the concern that the types of analysts covering a given M\&A might be correlated with M\&A characteristics, such as M\&A size, whether an acquirer and a target are in the same industry, whether an M\&A is part of an M\&A wave, and/or the aggregate information environment. ${ }^{8}$

\footnotetext{
${ }^{8}$ For example, we find that the increase in forecast errors around M\&As is around one-third lower in related M\&As. To the extent that related M\&As are correlated with analyst type, this might bias our results.
} 
Including no fixed effects would estimate the joint effect of both selection and treatment. Including analyst fixed effects (only) would allow selection effects to (still) influence our results as we would be making comparisons across brokerages. Lastly, including brokerage fixed effects (only) would hold organizational capital constant but compare across analysts. To the extent that any two analysts working at the same brokerage are interchangeable this would be fine. However, this is unlikely to be the case in reality.

Before proceeding to report our results, we mention a few additional facets of our general empirical approach. Our analysis is equivalent to a difference-in-differences (DiD) test. A common concern with DiD tests is that the treatment group and the counterfactual are significantly different from each other and that any findings we observe reflect those differences rather than the proposed treatment effect.

In our setting, this concern is less likely to play a role because the treatment group and the counterfactual represent the same group of analyst-broker pairs and inferences are made within those analyst-broker pairs. Relatedly, our empirical design exploits plausibly random variation in the organization of information within the same brokerage to understand the causal effects of information spillovers on performance. This allows us to absorb selection effects in a manner that would not be possible if we were to study the effect of organization on individual performance using a "fixed effects method," as in Bertrand and Schoar (2003). The fixed-effects method draws its power from analyzing changes in performance as an analyst moves from one brokerage to another. Most job transfers cannot be thought of as independent of the analyst-person-specific performance component; instead, they might represent promotions or demotions. Disentangling the treatment effects and selection effects using job transfers is thus difficult, if not impossible, to do.

Finally, earnings forecasts are only one of two primary quantifiable outputs that analysts produce. The second such output is an analyst's overall recommendation whether a stock should be bought, held, or sold. We focus on earnings forecasts as they can be easily evaluated against the actual earnings announced; stock recommendations lack such a clear objective benchmark. 


\section{Main Results}

We find that forecast errors, on average, are 0.058 higher for newly merged firms than for acquirer firms prior to M\&As. This increase in forecast errors represents a 33\% jump and is statistically significant from zero at the $1 \%$ level. The average analyst coverage for newly formed firms is 9.7 , compared with 8.1 for acquirers prior to M\&As. The increase in forecast errors is thus unlikely to be the result of lower information production by analysts or lower analyst competition (Hong and Kacperczyk 2010). Instead, the spike in forecast errors suggests that, at least initially, earnings for newly merged firms exhibit greater uncertainty and are harder to predict than those for acquirer firms prior to M\&As.

Table 3 reports the results from regression equation (2). Column (1) of Table 3 presents the results when including analyst-broker and M\&A fixed effects. We find that the change in forecast error is 0.020 lower when analysts are of Type 2 and 0.030 lower when analysts are of Type 3. Both estimates are statistically significant. The coefficient estimate of 0.030 is also statistically different from the estimate of $0.020(p$-value $<0.05)$.

In Column (2), we include a set of time-varying analyst characteristics as additional controls. The first control measures the time the analyst in question has been following the corresponding acquirer. To capture time variation in the analyst's work environment, we include the number of stocks the analyst follows, the number of GICS industry sectors the analyst follows, and the size of the analyst's team. In particular, we identify the modal GICS industry sector of the analyst and label that sector the analyst's "sector of expertise." Team size is the number of (other) analysts at the analyst's brokerage working in the analyst's sector of expertise.

When including these analyst characteristics, we observe that the change in forecast error is 0.020 lower when analysts are of Type 2 and 0.029 lower when analysts are of Type 3. Again, both estimates are statistically significant. The estimate of 0.029 remains statistically different from the estimate of $0.020(p$ value $<0.05){ }^{9}$

\footnotetext{
${ }^{9}$ One concern is whether analysts forecast earnings objectively or are influenced by the provision of M\&A advisory services. Using data from SDC Platinum, we classify each M\&A transaction as "dependent" or "independent" based on whether a brokerage for
} 
Together, our results suggest that information spillovers are an important determinant of individuallevel performance. Acquirer-analysts more successfully predict the performance of a newly formed firm when they can interact with colleagues and draw from in-house knowledge about the corresponding target firm. ${ }^{10}$ At the same time, our results suggest that some information is lost in translation as acquirer-analysts perform the best if, prior to M\&As, they cover both acquirer firms and target firms themselves.

\subsection{Robustness}

Because most analysts and some brokerages specialize in industries and since most M\&As are completed within a given industry, an M\&A in which an analyst is of Type 2 is more likely to be in an analyst's and broker's industry of expertise. An M\&A in which an analyst is of Type 1 is less likely to be in an analyst's and broker's industry of expertise. This, in turn, may partially account for our result that an analyst performs better when she is of Type 2 than when she is of Type 1 . To assess the validity of this concern we show, in Column (3) of Table 3, the results of considering only analyst-broker pairs that vary in type within a GICS sector and after including analyst-broker-sector fixed effects. Our results remain virtually unchanged. ${ }^{11}$

Another possible concern comes from our focus on acquirer analysts who continue to follow the newly formed firm after the M\&A. When analysts are of Type 1 , it is natural to choose them to cover newly formed firms. When analysts are of Type 2 and have in-house colleagues covering targets prior to M\&As, tournaments within the brokerages decide which of the two analysts cover the newly formed firm. The strong performance we observe when an analyst is of Type 2 may therefore be a positive selection effect rather than a true treatment effect.

\footnotetext{
which an analyst works is the main advisor in the transaction as measured by total fees. In untabulated results, we find that our results still hold within the subsample of independent brokers (both economically and statistically). Controlling for whether a brokerage advises a given $M \& A$ does not alter our main results.

${ }^{10}$ Further corroborating this view, we find that our information spillover effect disappears when looking at the subset of observations in which target analysts leave their brokers within three months of the completion of an M\&A (results available upon request).

${ }^{11}$ The number of observations drops from 15,939 to 14,770 because we now require variation in analyst type across M\&As within a given sector.
} 
Overall, we find that the vast majority of acquirer-analysts continue to cover newly formed firms even when they are of Type 2. In particular, we observe that $90.8 \%$ of Type 2 acquirer-analysts continue to cover newly formed firms, i.e., in only $9.2 \%$ of cases is it target-analysts who take over and cover newly formed firms. This strong imbalance is unlikely to be generated by differences in talent between acquirerand target-analysts and more likely reflects the fact that acquirer firms are generally much larger than target firms, making acquirer-analysts the more natural choice for covering newly formed firms. In line with this view, we find that the fraction of Type 2 acquirer-analysts who continue to cover newly formed firms almost monotonically increases with the size of acquirers relative to targets. For instance, when acquirers are at least five times larger than targets, $95.2 \%$ of Type 2 acquirer-analysts continue to cover newly formed firms.

In additional tests, we repeat our analysis within the subsample of M\&As for which acquirers are at least five times larger than targets and for which, ex ante, talent-based tournament effects are less likely to play a role. As reported in Column (4) of Table 3, our results only become stronger within this subsample.

A final concern with our interpretation is that analysts' learning from M\&As over time might be correlated with analyst type. For example, an analyst might start out as Type 1 and then become a Type 2 or Type 3 analyst (for the same brokerage). To address this concern we identify each analyst's first type in our sample. We find that analysts are essentially equally likely to start as Type 1 as they are to start as Type 2 or Type 3 analysts. Further, while our main results suggest that analysts perform the best when they are of Type 3, for the subset of analysts that are both of Type 2 and Type 3 at different points in their careers, we find that Type 3 precedes Type 2 in $65.4 \%$ of cases. This result contradicts the abovementioned learning story.

\subsection{The Nature of Information Sharing}

We next turn our attention to the channels through which organization affects performance. The efficacy of information spillovers relies both on the ability of agents to share information and the costs of information transmission. Applied to our setting, we expect two organizational attributes of a brokerage: 
geographical distance between analysts and team size, to affect the effectiveness of information transmission, in particular given the soft and subjective nature of the information being transmitted.

Some recent papers examine whether location clustering affects stock investment decisions. Ahern (2014) finds that insider trading is more prominent among traders in the same locale and that the profitability of trades decreases with distance. Hong, Kubik, and Stein (2005) find that mutual fund managers are more likely to trade stocks if other managers in the same locale trade the same stocks. Brown, Ivković, Smith, and Weisbenner (2008) suggest that retail investors share their investment decisions with peers in their communities.

To explore how geographical proximity affects information spillovers in our setting, we identify whether a brokerage has a single location and whether a Type 2 analyst and her peer covering the target are based in the same city. We find that $7 \%$ of Type 2 analysts work for brokers with a single location, and $32 \%$ of Type 2 analysts share a location with the peer who covers the target firm.

In the analysis tabulated in Column (1) of Table 4, we compare Type 2 analysts working at a singlelocation brokerage, Type 2 x Same Location, against Type 2 analysts, Type 2, and against Type 3 analysts, Type 3. Type 1 analysts serve as the counterfactual. We find that the coefficient estimate for Type 2 is 0.012 and not statistically significant. The estimate for Type $2 x$ Same Location is -0.033 and highly significant.

We repeat the analysis for analysts with peers residing in the same locale. As shown in Column (2) of Table 4, the coefficient estimate for Type 2 continues to be negative $(=-0.010)$ but not statistically significant, while the coefficient for Type $2 \times$ Same Location continues to be strongly negative $(=-0.029)$ and highly significant. The strong negative slope on the interaction term in both specifications suggests that information spillovers are greater when analysts share a location. The insignificant negative slope on Type 2 suggests that the information spillover effect is limited when analysts are geographically separated.

Interestingly, in both specifications, the estimate for Type $2 x$ Same Location is more negative than the estimate for Type 3, suggesting that when an analyst is of Type 2 and shares a location with a peer covering a target, she performs better than when she is of Type 3 . 
A second peer analyst characteristic that likely affects a Type 2 analyst's performance is the level of knowledge a peer has about a target. Peer analysts' understanding of targets likely grows with the number of years they have been covering such targets. We therefore experiment whether our spillover effect is stronger when target-analysts have been covering target firms for a longer period of time. We create an Experienced Peer dummy that equals one if the corresponding target-analyst's experience is above the $75^{\text {th }}$ percentile experience (= 4 years), and zero otherwise. As reported in Column (3) of Table 4 , both the coefficient estimate for Type 2 and the estimate for Type $2 \times$ Experienced Peer are negative and significant (-0.016 and -0.028 , respectively), suggesting that information spillover effects are particularly strong when a peer has been covering a target for a long time.

Next, we turn our attention to how team size affects information spillovers. Becker and Murphy (1992) argue that while specialization helps workers become more productive, increased specialization also makes it more difficult for workers to coordinate amongst each other, in particular if they are part of a larger team. Applied to our setting, we expect Type 2 analysts to find it more difficult to coordinate with peers if Type 2 analysts and their peers belong to larger teams.

We define Industry Team Size as the natural logarithm of the number of analysts specializing in a given industry sector at a given brokerage. Column (4) of Table 4 shows that the coefficient estimate for Type 2 is -0.021 and the estimate for Type $2 \times$ Industry Team Size is 0.015 . Both estimates are statistically significant. The positive estimate for the interaction term suggests that the information spillover effect decreases with team size.

In Column (5) of Table 4, we report the results of interacting Type 2 with the natural logarithm of the number of analysts working at the relevant brokerage, Broker Size, as an alternate measure of team size. We find that the interaction term between Type 2 and Broker Size is -0.016 albeit not statistically significant. One possible interpretation of the result that the spillover effect increases with Broker Size is that Broker Size captures organizational capital and the research support a brokerage provides, while Industry Team Size captures the coordination problems highlighted by Becker and Murphy (1992). 
Overall, the results reported in this subsection shed light on opportunities for and limitations on information sharing. Guided by theory, we provide evidence that greater geographical distance and team size increase communication and coordination costs between analysts, which, in turn, limits the degree of information sharing and spillovers. Perhaps not surprisingly, the information spillover effect is also affected by how knowledgeable the peers are.

\subsection{All-Star Analysts}

As alluded to before, top-performing individuals in the financial services industry quickly earn "superstar" status. The presence of star analysts has the following implications for our study. First, if analysts of Type 2 and Type 3 are systematically more likely to be of "superstar" status, then our prior results may be explained by the presence of stars. ${ }^{12}$ Second, stars likely command greater power within their firms. An analyst covering a target may therefore be more motivated to share information with an acquirer-analyst if the acquirer-analyst is a star analyst. ${ }^{13}$ Third, being of Type 2 might be particularly beneficial if the peer covering the target herself is a star and, as such, has a deeper understanding of and better connections to the target firm.

We identify star analysts as those included in the Institutional Investor's All-America Research Team, commonly known as “All-Star Analysts.” Dunbar (2000), Krigman, Shaw, and Womack (2001), and Clarke et al. (2007) provide evidence that firms value All-Star analysts when selecting underwriters and M\&A advisors. Leone and Wu (2007) document that these All-Star analysts achieve better earnings forecast accuracy, better stock recommendation returns, and smaller optimism bias than their non-star counterparts. ${ }^{14}$

\footnotetext{
${ }^{12}$ While we include analyst-broker fixed effects, there is time-series variation in All-Star status.

${ }^{13}$ Power, in this context, refers to an analyst's ability to create a critical resource that she controls - her human capital. See Rajan and Zingales (1998) for an exposition of power in the theory of the firm and access to information as a critical resource.

${ }^{14}$ Leone and $\mathrm{Wu}$ (2007) discuss the selection procedure for the All-American team. To summarize the procedure, selection to the All-American team is based on survey data. Institutional Investor sends out a questionnaire to the directors of research and chief investment officers of money management institutions and also to sell-side analysts. Survey participants rank each analyst along the following six dimensions: accessibility and responsiveness, earnings estimates, useful \& timely calls, stock selection, industry knowledge, and written reports. Scores for each analyst are calculated by taking the number of votes awarded by each survey
} 
In our sample, $11 \%$ of analyst-year observations represent All-Star observations. We find variation in All-Star status both across analysts and within analysts (across time). Examining All-Star status by analyst type, we find that $11 \%$ of Type 2-analyst observations represent All-Star observations; the corresponding number for Type 3-analyst observations is $13 \%$. Unconditionally, at least, this implies that All-Star status is not a determinant of Type 2 or Type 3 status.

We begin by testing whether our result that analysts perform better when they are of Type 2 or Type 3 is robust to accounting for All-Star status. The results presented in Column (1) of Table 5 answer in the affirmative. The estimate for Type 2 analysts and the estimate for Type 3 analysts do not change when controlling for All-Star status.

We next test whether the effect of being of Type 2 or Type 3 varies if the relevant acquirer-analyst is an All-Star. In particular, we interact Type 2 and Type 3 with an All-Star indicator. As reported in Column (2), we find that the estimate for the interaction between Type 2 and All-Star is -0.055 and statistically significant, suggesting that a peer covering a target is more strongly motivated to assist an acquirer-analyst if the acquirer-analyst has high status.

Finally, in Column (3), we report the results of examining whether there is a positive effect on an acquirer-analyst's performance when the corresponding peer covering the target is an All-Star. We estimate the same regression equation as in Column (2), but we now include an interaction between Type 2 and Peer is All-Star, which equals one if the corresponding target-analyst is an All-Star. The interaction produces a statistically significant negative slope of -0.040 , suggesting that being of Type 2 is particularly advantageous if peers are of high quality.

\subsection{The Aggregate Information Environment}

The information environment an analyst faces is a combination of the internal information environment that is set by the organizational structure - the focus of this study — and the information environment that is

respondent and weighting them by the size of the respondent's firm. The results are published each year in the October issue of the magazine. 
external to the organization. In our setting, the external information environment likely is affected by the number of analysts covering the acquirer and the target.

In this subsection, we examine how the external information environment - through analyst coverage - affects analyst performance around M\&As and relates to the information spillover effect. On average, there are 16 analysts covering an acquirer, while there are 6 analysts covering a target. The variation in coverage is not surprising given the relative sizes of acquirers and targets.

We begin by examining whether the number of analysts following acquirers and targets affects acquirer-analysts' forecast accuracy for newly formed firms. The results are reported in Column (1) of Table 6. We find that the coefficient estimate for Target Coverage is -0.002 and statistically significant, suggesting that uncertainty around earnings is lower when the external information environment for a target is richer. ${ }^{15}$ In contrast, the estimate for Acquirer Coverage is close to zero, suggesting that acquirer-analysts are already familiar with the acquirer and do not benefit if more "external" analysts cover the acquirer.

We next test whether there is an interaction effect between analyst target coverage and our information spillover effect. As reported in Column (2) of Table 6, we find no reliable interaction between Type 2 and target coverage.

\subsection{Specialization}

We also examine how specialization affects the performance of analysts and relates to our information spillover effect. Specialization equals one if an M\&A sector matches the sectoral specialization of an analyst, which is identified as the modal sector from the universe of firms that the analyst covers. On average, analysts cover 2.5 sectors and $73 \%$ of M\&A activity is in their sectors of expertise. As reported in Column (3) of Table 6, we find that the inclusion of this variable has virtually no effect on our estimates for Type 2 and Type 3. We also find that the coefficient estimate for Specialization is -0.024 and significant, suggesting that analysts perform better when M\&As are in their sectors of expertise.

\footnotetext{
${ }^{15}$ In Column (1) of Table 6, we omit M\&A fixed effects and, instead, apply year fixed effects because the variables of interest, target and acquirer-analyst coverage, vary at the M\&A level.
} 
In Column (4) of Table 6, we examine whether Specialization moderates with the information spillover effect. We find that neither the interaction term between Specialization and Type 2 nor the interaction term between Specialization and Type 3 is reliably different from zero. We thus fail to detect the presence of a strong moderating effect of specialization on information spillover.

\section{Identification Concerns}

In sum, our results provide an estimate of how performance varies with how information is structured within an organization. Our results imply that there is information spillover, which positively impacts individual performance. Our study thus concludes that organization matters for individual performance. Here, we discuss some final identification concerns.

There may be confounding events in the two-year window before and after an M\&A. If the confounding events affect forecast errors non-randomly across analyst type, our analysis suffers from an omitted variable bias. To mitigate this concern, we re-estimate our main results with a six-month window before and after an M\&A. As shown in Column (1) of Table 7, our results continue to hold.

A second concern is that our results may be due to selective disclosure. On August 15, 2000, the SEC adopted Regulation FD to address selective disclosure of information by publicly traded companies and other issuers. Regulation FD mandates that when an issuer discloses material nonpublic information to certain individuals or entities, the issuer must make full public disclosure of that information. To mitigate concerns that our results are due to selective disclosure and also to assess whether our results hold in later years when communication costs may have decreased, we re-run our main specification for the period running from 2000 through 2011. We present the results in Column (2) of Table 7. Once again, the main results continue to hold.

Third, we allow for the possibility that our results are due to differences in pre-M\&A earnings forecast errors across analyst types. The descriptive statistics presented in Table 2 suggest this is not the case, but, here, we formally rule out this selection concern. We re-estimate our main specification, but replace the dependent variable with Pre-M\&A Forecast Error. Neither the estimate for Type 2 nor the 
estimate for Type 3 is reliably different from zero, suggesting that there is no difference in pre-M\&A earnings forecast error across analyst types.

A further concern is that analyst performance by type is a function of heterogeneity in the level of information production rather than information spillovers. Specifically, if analysts systematically revise earnings forecasts more often when they are of Type 2 than when they are of Type 1, this may result in their providing more accurate forecasts. In Column (4) of Table 7, we report the results of examining whether productivity varies by analyst type by computing the change in the number of revisions for an analyst-broker around an M\&A, $\Delta$ Revisions $_{i, j, m, t}=\overline{\text { Revlslons }_{l, j, m, p o s t}}-\overline{\text { Revlslons }_{l, j, m, p r e}}$, and using $\Delta$ Revisions $_{i, j, m, t}$ as our dependent variable in our main specification. We find no link between analyst type and information production as both the estimate for Type 2 and the estimate for Type 3 are not reliably different from zero. Thus, it appears that information spillovers affect individual performance without affecting individual productivity.

Finally, we take advantage of failed mergers to provide a placebo test to show that our results are not due to selection of analysts into M\&As. We follow Seru (2014) and identify 726 M\&As that were announced but unsuccessful using SDC Platinum. ${ }^{16} \mathrm{We}$ are able to match 241 of these failed M\&As with the IBES data required to examine forecast accuracy for potential acquirers both before and after merger withdrawal dates. To apply the same empirical strategy as in our main tests, we require variation in analyst type within analyst-broker pairs. Our final sample includes 1,030 forecasts from 365 analyst-broker pairs covering 180 failed M\&As.

On average, the change in forecast error around failed M\&As is -0.0087. In Column (5) of Table 7, we report the results of estimating our main regression equation on the failed M\&A sample. In short, we

\footnotetext{
${ }^{16}$ We collect our own sample of failed mergers given that the sample period in Seru (2014) does not match our sample period. Specifically, we identify failed mergers in SDC Platinum by applying the following filters: 1) the announcement date falls between 1983 and 2011, 2) the acquirer and target are both U.S. public firms, 3) the acquirer's market capitalization exceeds $\$ 10$ million, 4) the pre-announcement market value of the target is at least $5 \%$ of the acquirer's market value, 5) the bidder seeks to own $100 \%$, and 6) the bid failed.
} 
find no effect of analyst type on analyst performance as neither the estimate for Type 2 nor the estimate for Type 3 is reliably different from zero.

\section{Conclusion}

In this paper, we provide evidence of information spillovers within organizations that positively affect individual performance. In particular, we provide evidence that analysts covering acquirers prior to M\&As struggle predicting the performance of newly formed firms, at least initially. Acquirer-analysts perform substantially better when they have in-house colleagues covering targets prior to M\&As. At the same time, we find evidence of frictions in information sharing as acquirer-analysts perform best if they themselves cover both acquirers and targets prior to M\&As. Our evidence reveals that these frictions are largely offset when acquirer- and target-analysts reside in the same locale, acquirer- and target-analysts are part of a small team and when target-analysts are likely of higher quality.

Our research setting has two appealing features. First, we can measure individual performance in the form of earnings forecast accuracy. Second, we can contrast, for a given analyst working at a given brokerage, the analyst's performance around M\&As for which she has an in-house colleague covering the corresponding target against her performance around M\&As for which she has no such colleague. We propose that our within-analyst-broker estimation absorbs selection effects that typically plague studies examining whether organization affects individual performance.

The findings of this paper highlight the importance of information and knowledge as a critical resource and relate to the broader discussion of human capital in the theory of the firm. Our results suggest that organizations are important when explaining individual performance and help shed light on whether high-performing firms create highly productive individuals or simply hire highly productive individuals. 


\section{References}

Agarwal, S. and R. Hauswald, 2010, "Distance and Private Information in Lending," Review of Financial Studies, 23 (7), 2757-2788.

Aghion, P., and J. Tirole. 1997, "Formal and Real Authority in Organizations," The Journal of Political Economy, 105 (1), 1-29.

Ahern, K.R., 2017, "Information Networks: Evidence from Illegal Insider Trading Tips," Journal of Financial Economics, 125 (1), 26-47.

Bandiera O., I. Barankay and I. Rasul, 2005, "Social Preferences and the Response to Incentives: Evidence from Personnel Data," The Quarterly Journal of Economics, 120 (3), 917-962.

Bertrand, M. and A. Schoar, 2003, "Managing with Style: The Effect of Managers on Firm Policies", The Quarterly Journal of Economics, 118 (4), 1169-1208.

Becker, G.S., 1973, “A Theory of Marriage: Part I,” The Journal of Political Economy, 81 (4), 813-846.

Becker, G.S., 1993, A Treatise on the Family, Enlarged Edition, Harvard University Press.

Becker, G.S and K.M. Murphy, 1992, "The Division of Labor, Coordination Costs, and Knowledge," The Quarterly Journal of Economics, 107 (4), 1137-1160.

Beshears, J., 2013, "The Performance of Corporate Alliances: Evidences from Oil and Gas Drilling in the Gulf of Mexico," Journal of Financial Economics, 110 (2), 324-346.

Bloom, N., L. Garicano, R. Sadun and J.Van Reenen, 2014, "The Distinct Effect of Communication Technology and Information Technology on Firm Organization," Management Science, 60 (12), 2859-2885.

Bolton, P., and M. Dewatripont, 1994, "The Firm as a Communication Network," The Quarterly Journal of Economics, 109 (4), 809-830.

Brown, J. Z. Ivković, P. Smith, and S. Weisbenner, 2008, "Neighbors Matter: Causal Community Effects and Stock Market Participation," The Journal of Finance, 63 (3): 1509-1531.

Clarke, J., A. Khorana, A. Patel, and R. Rau, 2007, "The Impact of All-Star Analyst Job Changes on their Coverage Choices and Investment Banking Deal Flow," Journal of Financial Economics, 84 (3), 713-737.

Coase, R.H., 1937, “The Nature of the Firm,” Economica, 4 (16), 386-405.

Coase, R. H., 1988, “The Nature of the Firm: Origin, Meaning, Influence,” Journal of Law, Economics, and Organization, 4 (1), 3-17.

Cohen, L., A. Frazzini, and C. Malloy. "The Small World of Investing: Board Connections and Mutual Fund Returns," Journal of Political Economy 116 (5), 951-979. 
Dunbar, C.G., 2000, "Factors Affecting Investment Bank Initial Public Offering Market Share," Journal of Financial Economics, 55 (1), 3-41.

Ewens, M. and M. Rhodes-Kropf, 2015, "Is a VC Partnership Greater than the Sum of Its Partners?," Journal of Finance, 70 (3), 1081-1113.

Garicano, L., 2000, "Hierarchies and the Organization of Knowledge in Production," The Journal of Political Economy, 108 (5), 874-904.

Garicano, L., and E. Rossi-Hansberg, 2006, "Organization and Inequality in a Knowledge Economy," The Quarterly Journal of Economics, 121 (4), 1383-1435.

Groysberg, B., 2010, Chasing Stars, Princeton University Press, 2010.

Groysberg, B., Lee, L.E. \& Nanda, A., 2008, "Can They Take it with Them?: The Portability of Star Knowledge Workers’ Performance,” Management Science, 54 (7), 1213-1230.

Gupta-Mukherjee, S., 2014, "Investing in the 'New Economy': Mutual Fund Performance and the Nature of the Firm" Journal of Financial and Quantitative Analysis, 49 (1), 165-191.

Hart, O., 1989, “An Economist's Perspective on the Theory of the Firm”, Columbia Law Review, 89 (7), $1757-1774$.

Hong, H. and M. Kacperczyk, 2010, “Competition and Bias," The Quarterly Journal of Economics, 125 (4), 1683-1725.

Hong, H., J. D. Kubik and J. C. Stein, 2005. "Thy Neighbor's Portfolio: Word-of-Mouth Effect in the Holdings and Trades of Money Managers," The Journal of Finance, 60 (6), 2801-2824.

Ivashina, V. and S. Zhen, 2011, "Institutional Stock Trading on Loan Market Information," Journal of Financial Economics, 100 (2), 284-303.

Kim, E.H., A. Morse and L. Zingales, 2009, "Are Elite Universities Losing their Competitive Edge?," Journal of Financial Economics, 93 (3), 353-381.

Klein, B., 1988, "Vertical Integration as Organizational Ownership: The Fisher Body-General Motors Relationship Revisited," Journal of Law, Economics and Organization, 4 (1), 199-213.

Kothari, S.P., 2001, "Capital Markets Research in Accounting," Journal of Accounting and Economics, 31 (1), 105-231.

Krigman, L., W.H. Shaw, and K.L. Womack, 2001, "Why Do Firms Switch Underwriters?,” Journal of Financial Economics, 60 (2-3), 245-284.

Landier, A., V.B. Nair and J. Wulf, 2009, "Trade-offs in Staying Close: Corporate Decision Making and Geographic Dispersion," Review of Financial Studies, 22 (3), 1119-1148.

Leone, A. and J.S. Wu, 2007, "What Does it Take to Become a Superstar? Evidence from Institutional Investor Rankings of Financial Analysts?," University of Miami, Working Paper. 
Liberti, J. M., 2017, “Initiative, Incentives and Soft Information,” Management Science, forthcoming.

Liberti, J.M. and A.R. Mian, 2009, "Estimating the Effects of Hierarchies on Information Use," Review of Financial Studies, 22 (10), 4057-4090.

Liberti, J.M., A. Seru and V. Vig, 2017, "Information, Credit and Organization," Stanford Graduate School of Business, Working Paper.

Loh, R. and R. Stulz, 2017, "Is Sell-Side Research More Valuable in Bad Times?” The Journal of Finance, forthcoming.

Mas, A. and E. Moretti, "Peers at Work," American Economic Review, 99 (1), 2009.

Massa, M. and Z. Rehman, 2008, "Information Flows within Financial Conglomerates: Evidence from the Banks-Mutual Funds Relation,” Journal of Financial Economics, 89 (2), 288-306.

Mian, A.R., 2006, "Distance Constraints: The Limits of Foreign Lending in Poor Economies," The Journal of Finance, 61 (3), 1465-1505.

Mullainathan, S. and D. Scharfstein, 2001, "Do Firm Boundaries Matter?," American Economic Review Papers and Proceedings, 91(2), 195-199.

Petersen, M. and R.G. Rajan, 2002, "Does Distance Still Matter? The Information Revolution in Small Business Lending," The Journal of Finance, 57 (6), 2533-2570.

Radner, R., 1993, "The Organization of Decentralized Information Processing," Econometrica, 61 (5), 1109-1146.

Rajan, R.G. and L. Zingales, 1998, "Power in a Theory of the Firm," The Quarterly Journal of Economics, 113 (2), 397-432.

Rajan, R.G. and L. Zingales, 2001, "The Firm as a Dedicated Hierarchy: A Theory of the Origins and Growth of Firms," 116 (3), 805-852.

Seru, A., "Firm Boundaries Matter: Evidence from Conglomerates and R\&D Activity," Journal of Financial Economics, 111 (2), 381-405.

Shimer, R. and L. Smith, 2000, “Assortative Matching and Search,” Econometrica, 68 (2), 343-369.

Sialm, C., and Tham, Y., 2016, "Spillover Effects in Mutual Fund Companies," Management Science, 62 (5), 1472-1486

Stein, J., 2002, "Information Production and Capital Allocation: Decentralized Versus Hierarchical Firms," The Journal of Finance, 57 (5), 1891-1921.

Stickel, S.E., 1995, "The Anatomy of the Performance of Buy and Sell Recommendations," Financial Analyst Journal, 51 (1), 25-39.

Womack, K.L., 1996, “Do Brokerage Analysts' Recommendations have Investment Value?,” The Journal of Finance, 51 (1), 137-167. 
Table 1

M\&A Descriptive Statistics

This table reports descriptive statistics for the 2,403 firm M\&As used in the study. Acquirer Size and Target Size are the market capitalizations of the acquirer and the target, respectively, measured in millions of dollars in the quarter prior to the M\&A. Target as \% of Merged Firm is the ratio Target Size to (Acquirer Size + Target Size). Related M\&A is a dummy variable that equals one if the acquirer and the target are in the same GICS sector. Acquirer Analyst Coverage and Target Analyst Coverage are the number of analysts following the acquirer and the target, respectively, in the period prior to the M\&A.

\begin{tabular}{lcccccc}
\hline & & & & \multicolumn{3}{c}{ Percentiles } \\
\cline { 6 - 7 } & $\mathrm{N}$ & Mean & St. Dev & 25th & 50th & 75th \\
\hline \multirow{2}{*}{ Acquirer Size $(\$ \mathrm{MM})$} & 2,403 & 11,781 & 38,411 & 692 & 2,047 & 7,013 \\
Target Size $(\$ \mathrm{MM})$ & 2,403 & 1,975 & 6,702 & 95 & 285 & 1,055 \\
Target as \% of Merged Firm & 2,403 & 0.2 & 0.18 & 0.05 & 0.15 & 0.32 \\
Related M\&A & 2,403 & 0.68 & 0.47 & 0 & 1 & 1 \\
Acquirer Analyst Coverage & 2,403 & 16.1 & 11.11 & 8 & 13 & 22 \\
Target Analyst Coverage & 2,403 & 5.97 & 6.52 & 2 & 4 & 8 \\
\hline
\end{tabular}


Table 2

Analyst Characteristics by Information Environment

This table reports descriptive statistics for the main variables used in this study. Our sample contains 2,878 analystbrokerage pairs, composed of 2,394 analysts working for 215 brokers covering 2,403 M\&As. In total, we have 15,939 analyst-stock pairs of which 10,921 are by "Type 1 analysts" and of which 5,018 are in an information environment with "overlap" in coverage. Of those 5,018 pairs, 1,468 exhibit overlap at the brokerage-level, i.e., they represent situations in which the acquirer-analyst has a colleague working at the same brokerage covering the target prior to the M\&A (三 "Type 2 analysts"); 3,550 exhibit overlap at the analyst-level, i.e., they represent situations in which the acquirer-analyst also covers the target prior to the M\&A (三 "Type 3 analysts"). Forecast Error prior to M\&A is defined as the absolute difference between analyst $i$ 's most recent quarterly earnings-per-share (EPS) forecast and the actual quarterly EPS, divided by the stock price as of the corresponding fiscal quarter end for the period prior to the M\&A. We require EPS forecasts to be issued/updated at least once in the three months prior to the earnings announcement. $\Delta$ Forecast Bias is the average forecast bias after the M\&A minus the average forecast bias prior to the M\&A; forecast bias is the difference between the analyst's most recent EPS forecast and the actual announced EPS, divided by the stock price as of the corresponding fiscal quarter end. Forecast Horizon is the number of days between the forecast date and the earnings announcement date. Firm-Specific Experience is the number of years the analyst has been covering the acquirer. Number of Stocks Covered is the number of stocks covered by the analyst. Number of Sectors Covered measures the number of GICS Sectors covered by the analyst. \%Analysts Based in New York is the fraction of analysts based in New York. Acquirer Size (\$MM), Target Size (\$MM), Target as \% of Merged Firm, and Related $M \& A$ are as described in Table 1.

\begin{tabular}{|c|c|c|c|c|}
\hline & & \multirow[b]{2}{*}{$\begin{array}{c}\text { No Overlap } \\
\text { (Type } 1)\end{array}$} & \multicolumn{2}{|c|}{ Overlap at the } \\
\hline & & & $\begin{array}{c}\text { Brokerage-Level } \\
\text { (Type 2) }\end{array}$ & $\begin{array}{c}\text { Analyst-Level } \\
\text { (Type 3) }\end{array}$ \\
\hline & $(1)$ & $(2)$ & (3) & (4) \\
\hline \#Analyst-Stock Pairs & 15,939 & 10,921 & 1,468 & 3,550 \\
\hline Forecast Error prior to M\&A & 0.17 & 0.17 & 0.16 & 0.18 \\
\hline$\Delta$ Forecast Bias & -0.04 & -0.04 & -0.04 & -0.04 \\
\hline Forecast Horizon & 48 & 48 & 46 & 47 \\
\hline Firm-Specific Experience & 4.27 & 4.22 & 4.06 & 4.52 \\
\hline Number of Stocks Covered & 18.61 & 18.64 & 16.50 & 19.38 \\
\hline Number of Sectors Covered & 2.08 & 2.04 & 1.96 & 2.26 \\
\hline$\%$ Analysts Based in New York & 0.27 & 0.26 & 0.30 & 0.29 \\
\hline Acquirer Size (\$MM) & 20,645 & 19,582 & 35,300 & 17,831 \\
\hline Target Size (\$MM) & 3,281 & 1,500 & 6,331 & 6,940 \\
\hline Target as $\%$ of Merged Firm & 0.19 & 0.14 & 0.21 & 0.31 \\
\hline Related M\&A & 0.71 & 0.67 & 0.75 & 0.79 \\
\hline
\end{tabular}


Table 3

Analyst Performance and Information Spillovers

This table reports OLS estimates of regressions from $\Delta$ Forecast Error on analyst-type variables. For each analyststock pair, we measure $\Delta$ Forecast Error as the percentage difference in the mean forecast error post-M\&A and the mean forecast error pre-M\&A. Forecast Error is defined as the absolute difference between analyst $i$ 's most recent quarterly earnings-per-share (EPS) forecast and the actual quarterly EPS, divided by the stock price as of the corresponding fiscal quarter end. We require EPS forecasts to be issued/updated at least once in the three months prior to the earnings announcement. We compute the forecast error for quarterly earnings announced in the two yearwindow around the effective date of the M\&A. Type 2 equals one if the acquirer-analyst has a colleague working at the same brokerage covering the target prior to the M\&A. Type 3 equals one if the acquirer-analyst also covers the target prior to the M\&A. Specifications include analyst-broker fixed effects (Columns (1), (2), and (4)) and M\&A fixed effects (Columns (1) - (4)). Column (3) includes analyst-broker-sector fixed effects. Columns (2) through (4) include time-varying analyst characteristics. The analyst characteristics include Firm-Specific Experience, Number of Stocks Covered, Number of Sectors Covered, and Team Size. The samples in Columns (3) and (4) contain only analystbroker pairs that have variation in type within a GICS sector and pairs for which the acquirer is five times the size of the target, respectively. Standard errors are reported in parentheses and are computed after allowing for correlations across observations in a given broker-analyst and M\&A. *,** and *** represent statistical significance at the 10,5 and 1 percent levels.

\begin{tabular}{ccccc}
\multicolumn{2}{c}{ Full Sample } & & \multicolumn{2}{c}{ Subsample } \\
$\begin{array}{c}\text { Analyst-Broker } \\
\text { and M\&A FE }\end{array}$ & $\begin{array}{c}\text { Full } \\
\text { Specification }\end{array}$ & & $\begin{array}{c}\text { Variation in Type } \\
\text { Within Sector }\end{array}$ & $\begin{array}{c}\text { Acquirer Size }> \\
5 x \text { Target Size }\end{array}$ \\
\hline$-0.020^{*}$ & $(2)$ & $(3)$ & $(4)$ \\
$(0.010)$ & $-0.020^{*}$ & $(0.010)$ & $-0.020^{*}$ & $-0.022^{*}$ \\
$-0.030^{* * *}$ & $-0.029^{* * *}$ & $(0.010)$ & $(0.013)$ \\
$(0.008)$ & $(0.008)$ & $-0.030^{* * *}$ & $-0.022^{* *}$ \\
& & $(0.009)$ & $(0.009)$ \\
No & Yes & & Yes \\
Yes & Yes & Yes & Yes \\
No & No & No & No \\
Yes & Yes & Yes & Yes \\
15,939 & 15,939 & 14,770 & 9,956 \\
0.79 & 0.79 & 0.82 & 0.81
\end{tabular}


Table 4

Analyst Performance and the Nature of Spillovers

This table replicates Table 3, but includes the following interaction terms and additional controls: Same Location captures whether the Type 2 analyst works for a brokerage with a single location (Column (1)) or whether the Type 2 analyst works for a brokerage with multiple locations, but the Type 2 analyst and the peer following the target reside in the same locale (Column (2)). Experienced Peer is a dummy variable that equals one if the number of years the peer had been covering target is in the top quartile of its distribution. Industry Team Size is the natural logarithm of the number of in-house colleagues working within the acquirer's GICS sector. Broker Size is the number of analysts working at the acquirer-analyst's brokerage. Standard errors are reported in parentheses and are computed after allowing for correlations across observations in a given broker-analyst and M\&A. *,** and *** represent statistical significance at the 10,5 and 1 percent levels.

\begin{tabular}{|c|c|c|c|c|c|}
\hline & $\begin{array}{c}\text { Single-Location } \\
\text { Broker } \\
\text { (1) }\end{array}$ & $\begin{array}{l}\text { Analysts in same } \\
\text { Locale } \\
\text { (2) }\end{array}$ & $\begin{array}{c}\text { Peer } \\
\text { Experience } \\
\text { (3) }\end{array}$ & $\begin{array}{c}\text { Industry Team } \\
\text { Size } \\
(4)\end{array}$ & $\begin{array}{l}\text { Broker } \\
\text { Size } \\
(5)\end{array}$ \\
\hline Type 2 & $\begin{array}{l}-0.012 \\
(0.011)\end{array}$ & $\begin{array}{l}-0.010 \\
(0.012)\end{array}$ & $\begin{array}{c}-0.016^{*} \\
(0.010)\end{array}$ & $\begin{array}{c}-0.021^{* *} \\
(0.010)\end{array}$ & $\begin{array}{c}-0.018^{*} \\
(0.010)\end{array}$ \\
\hline Type $2 \times$ Same Location & $\begin{array}{c}-0.033^{* *} \\
(0.016)\end{array}$ & $\begin{array}{c}-0.029 * \\
(0.016)\end{array}$ & & & \\
\hline Type 3 & $\begin{array}{c}-0.029 * * * \\
(0.008)\end{array}$ & $\begin{array}{c}-0.029 * * * \\
(0.008)\end{array}$ & $\begin{array}{c}-0.029^{* * *} \\
(0.008)\end{array}$ & $\begin{array}{c}-0.030^{* * *} \\
(0.008)\end{array}$ & $\begin{array}{c}-0.030^{* * *} \\
(0.008)\end{array}$ \\
\hline Type $2 \times$ Experienced Peer & & & $\begin{array}{c}-0.028^{*} \\
(0.015)\end{array}$ & & \\
\hline Type $2 \times$ Industry Team Size & & & & $\begin{array}{c}0.015 * * \\
(0.007)\end{array}$ & $\begin{array}{c}0.015^{* *} \\
(0.007)\end{array}$ \\
\hline Type $2 \times$ Broker Size & & & & & $\begin{array}{l}-0.016 \\
(0.011)\end{array}$ \\
\hline Industry Team Size & & & & $\begin{array}{c}0.006 \\
(0.016)\end{array}$ & $\begin{array}{c}0.006 \\
(0.016)\end{array}$ \\
\hline Broker Size & & & & & $\begin{array}{c}0.020 \\
(0.020)\end{array}$ \\
\hline Analyst Characteristics & Yes & Yes & Yes & Yes & Yes \\
\hline Analyst-Broker Fixed Effects & Yes & Yes & Yes & Yes & Yes \\
\hline M\&A Fixed Effects & Yes & Yes & Yes & Yes & Yes \\
\hline Observations & 15,939 & 15,939 & 15,939 & 15,939 & 15,939 \\
\hline R-squared & 0.81 & 0.81 & 0.81 & 0.81 & 0.81 \\
\hline
\end{tabular}


Table 5

Analyst Performance and the Role of Skill

This table replicates Table 3, but includes the following interaction terms and additional controls: All-Star and Peer is All-Star equal one if the acquirer-analyst and the peer covering the target, in year $t$, are part of the Institutional Investors All-America Research Team, respectively. Standard errors are reported in parentheses and are computed after allowing for correlations across observations in a given broker-analyst and M\&A. *, ** and *** represent statistical significance at the 10,5 and 1 percent levels.

\begin{tabular}{lccc}
\hline & $(1)$ & $(2)$ & $(3)$ \\
\hline Type 2 & $-0.020^{* *}$ & -0.014 & $-0.017^{*}$ \\
Type 3 & $(0.010)$ & $(0.010)$ & $(0.010)$ \\
& $-0.029^{* * *}$ & $-0.027^{* * *}$ & $-0.027^{* * *}$ \\
Type 2 $\times$ All-Star & $(0.008)$ & $(0.009)$ & $(0.009)$ \\
& & $-0.055^{*}$ & $-0.048^{*}$ \\
Type 2 $\times$ Peer is All-Star & & $(0.028)$ & $(0.028)$ \\
& & & $-0.040^{*}$ \\
Type 3 $\times$ All-Star & & & $(0.025)$ \\
& & -0.020 & -0.020 \\
All-Star & 0.003 & $(0.015)$ & $(0.015)$ \\
& $(0.017)$ & 0.013 & 0.013 \\
Analyst Characteristics & & $(0.018)$ & $(0.018)$ \\
Analyst-Broker Fixed Effects & Yes & Yes & Yes \\
M\&A Fixed Effects & Yes & Yes & Yes \\
Observations & Yes & Yes & Yes \\
R-squared & 15,939 & 15,939 & 15,939 \\
& 0.81 & 0.81 & 0.81 \\
\hline
\end{tabular}


Table 6

Analyst Performance, Aggregate Information Environment, and the Role of Specialization

This table replicates Table 3, but includes the following interaction terms and additional controls: Target Coverage and Acquirer Coverage are the number of analysts following the target and the acquirer prior to the M\&A, respectively. Specialization is a dummy variable that equals one if the M\&A sector matches the sectoral specialization of the analyst, which is identified as the modal sector from the universe of firms that the analyst covers. Standard errors are reported in parentheses and are computed after allowing for correlations across observations in a given broker-analyst and M\&A. *, ** and *** represent statistical significance at the 10,5 and 1 percent levels.

\begin{tabular}{|c|c|c|c|c|}
\hline & \multicolumn{2}{|c|}{ Aggregate Information Environment } & \multicolumn{2}{|c|}{ Role of Specialization } \\
\hline & (1) & (2) & (3) & (4) \\
\hline Type 2 & & $\begin{array}{l}-0.018^{*} \\
(0.010)\end{array}$ & $\begin{array}{l}-0.020^{*} \\
(0.010)\end{array}$ & $\begin{array}{l}-0.017 * \\
(0.011)\end{array}$ \\
\hline Type 3 & & $\begin{array}{c}-0.037 * * * \\
(0.009)\end{array}$ & $\begin{array}{c}-0.029 * * * \\
(0.008)\end{array}$ & $\begin{array}{c}-0.041 * * * \\
(0.013)\end{array}$ \\
\hline Type $2 \times$ Target Coverage & & $\begin{array}{c}0.001 \\
(0.001)\end{array}$ & & \\
\hline Type $3 \times$ Target Coverage & & $\begin{array}{c}0.002 * * \\
(0.001)\end{array}$ & & \\
\hline Target Coverage & $\begin{array}{c}-0.002^{* *} \\
(0.001)\end{array}$ & & & \\
\hline Acquirer Coverage & $\begin{array}{c}0.000 \\
(0.001)\end{array}$ & & & \\
\hline Type $2 \times$ Specialization & & & & $\begin{array}{l}-0.006 \\
(0.018)\end{array}$ \\
\hline Type $3 \times$ Specialization & & & & $\begin{array}{c}0.019 \\
(0.015)\end{array}$ \\
\hline Specialization & & & $\begin{array}{l}-0.024^{*} \\
(0.015)\end{array}$ & $\begin{array}{l}-0.027 * \\
(0.016)\end{array}$ \\
\hline Analyst Characteristics & Yes & Yes & Yes & Yes \\
\hline Analyst-Broker Fixed Effects & Yes & Yes & Yes & Yes \\
\hline Year Fixed Effects & Yes & No & No & No \\
\hline M\&A Fixed Effects & No & Yes & Yes & Yes \\
\hline Observations & 15,939 & 15,939 & 15,939 & 15,939 \\
\hline R-squared & 0.39 & 0.81 & 0.81 & 0.81 \\
\hline
\end{tabular}


Table 7

Identification Concerns

This table replicates Table 3 with the following modifications: In Column (1), we only consider the six-month period before and after the M\&A (as opposed to the two-year period). In Column (2), we re-estimate our regression equation for the 2000 - 2011 sample period. In Column (3), we examine if the pre-M\&A Forecast Error varies by analyst type. In Column (4), we examine if the change in information production around the M\&A varies by analyst type, where we measure the change in information production as the change in the number of forecast revisions made by an analyst. In Column (5), we estimate our regression equation on a sample of 180 announced but withdrawn M\&As ("Failed M\&As"). Standard errors are reported in parentheses and are computed after allowing for correlations across observations in a given broker-analyst and M\&A. *,** and *** represent statistical significance at the 10, 5 and 1 percent levels.

\begin{tabular}{|c|c|c|c|c|c|}
\hline & $\begin{array}{c}\Delta \text { Forecast Error, } \\
-/+6 \text { Months } \\
\text { (1) }\end{array}$ & $\begin{array}{c}\Delta \text { Forecast Error, } \\
\text { Post } 2000 \\
\text { (2) }\end{array}$ & $\begin{array}{c}\text { Pre-M\&A } \\
\text { Forecast Error } \\
\text { (3) }\end{array}$ & $\begin{array}{c}\Delta \# \text { Forecast } \\
\text { Revisions } \\
\text { (4) }\end{array}$ & $\begin{array}{c}\Delta \text { Forecast Error } \\
\text { around Failed M\&A } \\
\text { (5) }\end{array}$ \\
\hline Type 2 & $\begin{array}{c}-0.022^{* *} \\
(0.010)\end{array}$ & $\begin{array}{l}-0.035^{*} \\
(0.019)\end{array}$ & $\begin{array}{c}0.001 \\
(0.006)\end{array}$ & $\begin{array}{l}-0.003 \\
(0.027)\end{array}$ & $\begin{array}{l}-0.013 \\
(0.019)\end{array}$ \\
\hline Type 3 & $\begin{array}{c}-0.032 * * * \\
(0.010)\end{array}$ & $\begin{array}{c}-0.051 * * * \\
(0.017)\end{array}$ & $\begin{array}{c}0.003 \\
(0.007)\end{array}$ & $\begin{array}{c}0.021 \\
(0.022)\end{array}$ & $\begin{array}{c}0.008 \\
(0.016)\end{array}$ \\
\hline Analyst Characteristics & Yes & Yes & Yes & Yes & Yes \\
\hline Analyst-Broker Fixed Effects & Yes & Yes & Yes & Yes & Yes \\
\hline M\&A Fixed Effects & Yes & Yes & Yes & Yes & Yes \\
\hline Observations & 15,939 & 5,059 & 15,939 & 15,939 & 1,030 \\
\hline R-squared & 0.75 & 0.87 & 0.83 & 0.41 & 0.51 \\
\hline
\end{tabular}

